\title{
OS ARGONAUTAS DA RAZÃO \\ Da Fenomenologia à Teoria dos Sistemas
}

\author{
José Manuel Santos \\ Universidade da Beira Interior
}

\section{Husserl e os fenomenólogos da segunda geração}

A fenomenologia teve a sua origem numa reacção anti-metafísica. $O$ "retorno às próprias coisas" preconizado pelo seu principal fundador, Edmund Husserl, significava, negativamente, abdicar do ponto de vista de Deus, ou, se quisermos, da tentativa de responder à pergunta de Leibniz, "pourquoi y a-t-il quelque chose plutôt que rien?". Negativamente, o "retorno" fenomenológico marca a renúncia a uma imaginação especulativa que ainda caracterizava o idealismo alemão pós-kantiano. Positivamente, ele significa não apenas uma reabilitação da "certeza sensível", tão menosprezada por Hegel e que se toma, para Husserl, "intuição doadora de sentido", mas, sobretudo, uma análise da génese do sentido ao nível mais elementar da experiência sensível, do phainestai (do aparecer) do sensível. O conceito fenomenológico de fenómeno não remete para uma "aparência" ocultadora de uma inacessível "coisa em si"; nada se esconde por trás da aparição. E de nada adianta ver no sensível. a "expressão" do "absoluto". O que quer que isso seja, o "absoluto", tem de "se mostrar", sich ausweisen, não apenas "exprimir-se" por interposta pessoa. Todo o sentido que faça sentido deverá ser constituído, ou re-constituído, a partir do phainestai, do processo do aparecer sensível. Não se trata apenas de dar mais dignidade ao sensível, mas de o semantizar radicalmente. É nesta perspectiva que Husserl reivindica o título de "verdadeiro positivista".

Com a máxima do "retorno", a fenomenologia clássica aparece como uma filosofia minimalista, modesta ou mesmo pobre, no sentido em que renuncia às "grandes questões", como a da existência de Deus ou a do ser do mundo como universitas rerum (como totalidade), e prescinde de "conceitos 
monumentais", 1 para se concentrar naquilo a que poderíamos chamar uma "microsemântica", que deverá ocupar o lugar da "macrosemântica" especulativa da ontologia tradicional.

O problema que se torna manifesto nas obras dos fenomenólogos da segunda geração é que a reconstituição microsemântica do sentido mais elementar e original não traz consigo o solo firme que permitiria responder a todas as questões com sentido. Se a microsemântica fenomenológica apresenta a vantagem de escapar às incertezas das teses especulativas da macrosemântica metafísica ou ontológica, bem como de superar o distanciamento das suas ousadas "construções" em relação à experiência, ao sensível e à vida, a sua base não é tão sólida como parecia à primeira vista.

A constituição do sentido hic et nunc da experiência das coisas e do mundo faz-se na perspectiva da "finitude", o que significa que toda a certeza está sempre rodeada de um horizonte de incerteza, toda a "necessidade de essência" de um mar de contingência. Esta situação pode ser descrita através de uma metáfora marítima já utilizada por Kant. Um "retorno às próprias coisas" que prometia solidez corre o risco de conduzir à tarefa impossível de construir uma embarcação no alto mar.

É justamente a esta metáfora que recorre Eugen Fink, num texto de 1958 em que expõe de maneira muito clara os problemas herdados pela fenomenologia da segunda geração. A concluir um capítulo consagrado a uma crítica fenomenológica da que é, a seus olhos, a última versão digna de nota da metafísica moderna, a de Hegel, Fink escreve:

Não podemos desfazer-nos da nossa finitude, como se fosse um trajo andrajoso, para fruir da magnificência de um "saber absoluto". O homem nunca é, mesmo nas suas possibilidades mais altas, um deus disfarçado que poderia, a dada altura, tomar consciência da sua divindade. Os sonhos de uma metafísica absoluta já lá vão. Dito isto, a filosofia é uma atitude de aspiração do mais finito dos seres, visto que sabe da sua própria finitude, àquilo que mais é - e que se oculta perante nós na plenitude do seu ser. E, deste modo, aqueles que pensam são sempre temerários que se afastam das costas firmes, são argonautas da razão. ${ }^{2}$

1 Expressão utilizada por Husserl numa conversa com o jovem Helmut Plessner, na altura em que este lhe apresentou um projecto de tese de doutoramento, para ser orientada por ele, sobre as categorias da subjectividade na filosofia de Fichte.

2 E. Fink, Sein, Wahrheit, Welt. Vor-Fragen zum Problem des Phänomen-Begriffs, Haia, M. Nijhoff, 1958, p. 52. „Wir können unsere Endlichkeit nicht abwerfen wie ein schäbiges Gewand und in die Herrlichkeit eines ,absoluten Wissens" eingehen. Der Mensch ist nie, auch nicht in seinen höchsten Möglichkeiten, ein vermummter Gott, der seiner Göttlichkeit einmal inne werden könnte. Die Träume einer absoluten Metaphysik sind ausgeträumt. Die Philosophie aber ist ein sehnendes Verhalten des am meisten endlichen, weil um seine Endlichkeit wissenden Wesens zu dem, was am meisten ist - und in der Fülle seines Seins sich vor uns verbirgt. Und so sind die Denkenden immer Wagende, die von den festen 
Tudo se passa, portanto, como se a renúncia ao ponto de vista de Deus, à perspectiva de uma infinitude correlativa da plenitude do sentido, tivesse por preço uma experiência do género marítimo, semanticamente lacunar e fragmentária, instável e contingente. É sintomático que na fenomenologia de Merleau-Ponty, outro fenomenólogo da segunda geração, os exemplos mais recorrentes e mais cruciais de constituição digam respeito àquilo a que poderíamos chamar objectos complexos, quasi-objectos ou mesmo pseudo-objectos, tais como paisagens, cidades, atmosferas, ou seja "coisas", se nos for permitido, para simplificar, chamar-lhes assim, semanticamente muito incertas e ambíguas. Isto contrasta com os exercícios mais frequentes da fenomenologia de Husserl, as reiteradas análises da percepção de objectos empíricos simples e, de preferência, imóveis, graças às quais é mostrado como é possível lidar com o "infinito potencial" dos "perfis" (Abschattungen) ou perspectivas que temos das coisas sensíveis. Na perspectiva de Husserl este infinito potencial deveria ocupar o lugar do ilusório "infinito actual" da metafísica. E isto com claras vantagens: o infinito dos "perfis" da percepção sensível não exclui certezas, evidências, intuições "doadoras", sentidos plenos, erfüllter Sinn. A "transcendência" das coisas, e do mundo, seria semanticamente dominável a partir da imanência da consciência, da doação de sentido do sujeito constituinte enquanto sujeito "transcendental".

A fenomenologia da segunda geração está centrada numa profunda dúvida sobre esta possibilidade. Merleau-Ponty insiste enfaticamente nos "problemas da transcendência", que derivam do facto de haver transcendências que, ao contrário do que acontece no caso dos objectos empíricos da percepção, não dominamos pelo pensamento objectivante. A lista razoavelmente completa dos principais "fenómenos que me ultrapassam", que nenhum "sujeito transcendental" jamais poderá dominar, ou seja "constituir", é estabelecida numa passagem da Phénoménologie de la perception:

O problema da modalidade existencial do social vem juntar-se a todos os problemas da transcendência. Quer se trate do meu corpo, do mundo natural, do passado, do nascimento ou da morte, a questão é sempre de saber como posso estar aberto a fenómenos que me ultrapassam e que só existem na medida em que os retomo e os vivo.

Estes fenómenos "ultrapassam-me" no sentido em que não é possível torná-los evidentes e transparentes através de uma série de actos suplementares de visionamento e "constituição", do género dos que efectuo quando tenho

Küsten sich abstoßen: Argonauten der Vernunft. “Todas as traduções de termos, expressões e excertos de textos alemães e franceses apresentadas neste trabalho são da responsabilidade do seu autor. 
dúvidas sobre o aspecto da face de um objecto que não vejo do sítio em que estou, e me movimento (ou movo o objecto) para a ver. Trata-se de fenómenos em que se manifesta algo que, por natureza, como já escrevia Heidegger, "desde logo e geralmente, justamente, não se mostra", e fica "oculto" (verborgen). Uma maneira de fazer face a este problema poderia consistir em dar à fenomenologia uma inflexão "hemenêutica", ou seja, tentar "interpretar" o significado de experiências cujo sentido não é de imediato manifesto, e não se obtém através de um acréscimo de observação e "conhecimento", na perspectiva da "existência", do Dasein. Tal é, pelo menos até à "viragem" (Kehre) à publicação da sua obra principal, a opção de Heidegger. Não me parece ser, porém, a de Merleau-Ponty. A via proposta por este será antes algo a que poderíamos chamar, na linguagem de Fink, uma fenomenologia ou "ontologia do medium". Na linguagem de Merleau-Ponty poderíamos falar de uma fenomenologia da "comunicação com o mundo", dando ao termo "comunicação" o seu sentido original de participação num elemento "comum" à subjectividade e ao mundo, a que este autor chamará "carne" na sua fase final.

As transcendências em causa não nos são totalmente desconhecidas e inacessíveis. Todavia, o seu sentido oculto, o "invisível do visível", não se deixa captar nem por uma descrição dos processos de semantização objectivante (Husserl), nem por uma hermenêutica da existência, uma "analítica do Dasein". Para compreender esse sentido é necessária uma "fenomenologia indirecta" ou "fenomenologia da fenomenologia"s susceptível de revelar um irreflectido do medium, uma espontaneidade da "carne" - no caso em apreço, algo como uma espontaneidade da dinâmica do social.

\section{Luhmann e Husserl}

O objecto da teoria dos sistemas de Niklas Luhmann é, justamente, uma das problemáticas "transcendências" referidas por Merleau-Ponty, ou seja o "social". Todavia, pensar o social como "sistema" ou, mais precisamente, como um conjunto de "sistemas" acoplados não é a mesma coisa que pensá-lo como medium ontológico cuja dinâmica "irreflectida" cabe explicitar. O "sistema" é de certo modo o contrário do "medium", é local, fechado sobre si, auto-referencial e, sobretudo, eminentemente temporal. Dito isto, tanto as fenomenologias do medium como a teoria dos sistemas respondem ao mesmo desafio de construir algo de sólido em pleno mar. Tanto os fenomenólogos da segunda geração como o teórico dos sistemas são, como diria Fink, "argonautas da razão".

4 M. Heidegger, Sein und Zeit (1927), Tübingen, M. Niemeyer, 1977, p. 35. “[...] was sich zunächst und zumeist gerade nicht zeigt". 
Comecemos por algumas indicações muito sucintas sobre a teoria de Luhmann, destinadas aos que ignoram tudo da Systemtheorie. Para este autor, a sociedade moderna é composta por "sistemas sociais" relativamente autónomos e fechados, resultantes de um processo de "diferenciação funcional". Historicamente, a ideia subjacente ao conceito de "sistema social" é inspirada no facto de a organização das sociedades modernas não se fazer por distribuição em segmentos horizontais, como nas sociedades tribais, nem através de uma hierarquia vertical de castas ou classes (como clero, nobreza, povo), mas pela progressiva especialização funcional das actividades. A economia, a arte, o direito, a ciência são exemplos de "sistemas sociais". Para Luhmann, a autonomização e o fechamento crescentes dos sistemas, que se verificam na modernidade, põem radicalmente em causa a ideia central do mais antigo pensamento ocidental sobre a sociedade, a ideia de uma ordem reitora emanada de um centro, como no caso paradigmático da "política" em Aristóteles, que dominaria ou centralizaria todas as actividades sociais.

Do ponto de vista teórico que aqui nos interessa, convém dizer que o conceito luhmanniano de sistema não tem apenas por origem a cibernética mas igualmente, e de maneira determinante, a fenomenologia de Husserl. A "consciência constituinte" husserliana é, para Luhmann, o modelo perfeito e paradigmático do tipo de sistemas que lhe interessa, os quais se caracterizam pelo facto de operarem com aquilo a que se chama "sentido". Os sistemas puramente físicos, químicos ou biológicos não "operam com sentido", as consciências e os sistemas sociais sim. O ponto de partida desta tese, a vários títulos controversa, é uma concepção fenomenológica do que é sentido. Para Luhmann, tal como em Husserl, o acesso ao "sentido" faz-se através de uma "descrição fenomenológica daquilo que é verdadeiramente dado num vivido (Erleben) com sentido". ${ }^{6}$ Uma fenomenologia de primeira instância, da "descrição directa" das "microsemânticas" imanentes da consciência do Erleben, husserliana, portanto, constitui, assim, como que a base, ou, se quisermos os prolegómenos, da teoria dos sistemas.

Convém, no entanto, observar com algum cuidado o que retém, e não retém, a teoria dos sistemas do projecto fenomenológico de Husserl. Começando pela negativa, não retém a "função unificadora" (a Einheitsleistung, como escreve Luhmann) do sentido e da experiência atribuída por Husserl à "figura da subjectividade transcendental"? . Nesta rejeição a teoria dos sistemas

6 N. Luhmann, "Sinn als Grundbegriff der Soziologie", in J. Habermas; N. Luhmann, Theorie der Gesellschaft oder Sozialtechnologie, Frankfurt, Suhrkamp, 1971, p. 35. Ver igualmente Soziale Systeme, Frankfurt, Suhrkamp, 1984, p. 93 sq.

7 N. Luhmann, Die neuzeitliche Wissenschaft und die Phänomenologie, Viena, Picus Verlag, 1996, p. 49. 
está em concordância com a fenomenologia da segunda geração, ${ }^{8}$ a qual considera essa figura última do idealismo, essa representação de um sujeito "imortal" e "infinito", totalmente improdutiva, no âmbito das tarefas finitas da constituição microsemântica, para resolver os problemas mais agudos colocados por uma experiência cujos fenómenos mais marcantes e significativos "me ultrapassam". Dito isto, os motivos desta rejeição do "sujeito transcendental" não são os mesmos dos dois lados.

Na perspectiva de Luhmann, o que ele pretende é desligar o sentido da simples lógica do aparecer de conteúdos, e, portanto, também daquilo a que Merleau-Ponty chamou o "logos mais profundo" dos fenómenos. Este "logos" seria a linguagem da comunicação do corpo e do mundo, a qual, por si só, garantiria a unidade ontológica das duas faces do phainestai, a reciprocidade do sentant e do senti, a unidade da "carne", na versão de Merleau-Ponty, ou do "Walten der Welt" (domínio de um mundo que eu não domino), na de Fink. Ora, o que Luhmann critica na ideia do "sujeito transcendental" não é o distanciamento deste em relação ao mundo concreto e ao seu "logos profundo", não é um pretendido "esquecimento" do mundo, um "desenraizamento", mas, ao contrário, o excessivo peso "ontológico" de um tal sujeito. O que Luhmann retém da fenomenologia husserliana é, antes de mais, a dinâmica temporal dos actos de uma consciência - que para ele constitui o paradigma do "sistema" na produção de "sentido". O essencial, para Luhmann, não é a unidade ontológica do sujeito e dos conteúdos do vivido mas a dinâmica dos actos da consciência como "remissões" (Verweisungen) que transcendem o actual e o dado para constituir leques de possibilidades. O "sentido" passa, assim, a ser visto numa perspectiva predominantemente temporal. "Sentido é", para Luhmann, "a diferença entre o justamente actual e o horizonte das possibilidades desse actual". 9 Assim, enquanto "fenómeno", escreve Luhmann, "o sentido aparece (erscheint) sob a forma de um excedente de possibilidades de viver (Erleben) e de agir (Handeln)". ${ }^{10}$ É neste "excedente" que reside o principal problema da consciência, ou do "sistema", o qual assenta no facto de "haver constantemente mais possibilidades de viver e de agir do que aquelas que podem ser actualizadas". "Luhmann retira da fenomenologia de Husserl a possibilidade de pensar o "sentido", não a partir da "referência" (isto é do objecto) e do signo, como acontece habitualmente, e em particular nas teorias semióticas da significação, mas a partir do Erleben, e, portanto, como acontecimento no tempo e como produção e "selecção" de possibilidades.

8 Como nota o próprio Luhmann, referindo-se ao "abandono da figura do sujeito transcendental" na hermenêutica de Gadamer e na fenomenologia de Merleau-Ponty, neste último caso através do "centramento da teoria no Leib humano". Idem, ibidem, p. 48.

${ }^{11}$ Luhmann, Theorie der Gesellschaft oder Sozialtecnologie, op. cit., p. 32. 


\section{A unidade do mundo}

$\mathrm{Na}$ teoria dos sistemas encontramos dois conceitos de mundo. O primeiro é o de "mundo envolvente" ou "ambiente", Umwelt, que resulta da primeira diferença - no início não está uma identidade mas uma diferença -, que é a diferença traçada pela própria "formação auto-referencial do sistema", a diferença entre sistema e mundo ambiente, entre System e Umwelt. O segundo é o "mundo" (Welt) enquanto unidade da primeira diferença, síntese inconcebível do indiferenciado e da diferença. Os actos ou operações do "sistema" também fazem parte do "mundo", mas, por definição, não fazem parte do "ambiente". Luhmann equipara a diferença inicial sistema/mundo ambiente, System/Umwelt, que constitui o ponto de partida conceptual da sua teoria, ao conceito husserliano de intencionalidade e à correlação noesis/noema. "Consciência é consciência de algo"; isto supõe a diferença entre a "consciência" e esse "algo", entre a capacidade ou o acto de designar e o designado, visar e visado, bem como entre esse "algo", conteúdo determinado, e "tudo o resto" que é a parte indeterminada do "mundo ambiente".

Para Husserl, o "mundo" apresenta-se como "horizonte" ilimitado de possibilidades de determinação para um sujeito. A complicação que a teoria dos sistemas acrescenta reside na insistência de Luhmann na "auto-referência" do sujeito enquanto "sistema", ou seja na "complexidade interna" da própria consciência obrigada a efectuar "selecções" contingentes. A simples "determinação" das possibilidades do "horizonte", ou seja do mundo ambiente (Umwelt) ainda por determinar, está longe de resolver todos os problemas da complexidade do "mundo" (Welt), o qual inclui, enquanto tal, o processamento de sentido e as selecções da consciência. Nesta perspectiva, os "sistemas sociais", que, como bem viu Merleau-Ponty, "ultrapassam" os "sistemas psíquicos" (na linguagem de Luhmann), serão os instrumentos ou meios que permitirão fazer face a um tal excesso de complexidade, ou, dito de outro modo, regular a contingência do mundo resultante do choque das selecções das diferentes consciências que constituem o substrato material do social. O social é uma "ordem emergente" acima do mar das consciências. Não há, obviamente, sistemas sociais se não houver "sistemas psíquicos"; da mesma maneira que estes últimos não existiriam se não existissem sistemas biológicos.

Para Luhmann, a relação entre sistema e ambiente, e a fortiori entre sistema e mundo (no sentido absoluto de unidade da diferença inicial), não deve ser entendida como Abbild (mimesis, representação), que é o modo como a metafísica pensa a relação entre pensamento e ser. Para um sistema de tipo consciência, o "mundo ambiente" (Umwelt) é "dado sob a forma de sentido", 13 ou seja de possibilidades determináveis, isto é actualizáveis. Esta semantiza-

12 Luhmann, Die neuzeitlichen Wissenschaften und die Phänomenologie, Picus Verlag, Viena, 1996 , pp. 30 sq. e 34 sq.

13 Luhmann, Soziale Systeme, op. cit., p. 95. 
ção do mundo e a correspondente temporalização do sentido já se encontram na fenomenologia de Husserl. Já para este o mundo não é uma simples universitas rerum, uma totalidade de coisas, uma simples soma de objectos combináveis, mas um Verweisungszusammenhang, um complexo de remissões semânticas resultantes da intencionalidade da consciência ou, na linguagem de Luhmann, das "operações" dos sistemas.

Todavia, depois de adoptar este conceito de mundo, o que significa adoptar a semantização e a temporalização de um mundo "constituído" na perspectiva da consciência ou do sistema, Luhmann separa-se de Husserl na questão do "sujeito transcendental". O que motiva a separação neste ponto nevrálgico e faz com que Luhmann não seja fenomenólogo no sentido de Husserl?

Como escreve o teórico dos sistemas, o "ego transcendental" é o agente de uma "performance de unidade" (Einheitsleistung), ${ }^{14}$ ou seja, é ele que garante a unidade semântica do mundo. Isto na medida em que esse "ego" é a fonte de todo o sentido possível, do sentido de todas as "transcendências", 15 incluindo a transcendência "mundo". Além disso, graças à teoria husserliana dos "tipos" de experiências e de objectos, bem como das ontologias formais e materiais, o sujeito transcendental dispõe de uma poderosa grelha semântico-ontológica ordenadora de todos os objectos de uma experiência possível. Não há nada no mundo que não tenha sentido, e a tarefa da fenomenologia reside na descrição da actividade semântica da subjectividade transcendental, no "desvelar sistemático", na "explicitação" da "intencionalidade constituinte" do sentido. ${ }^{16}$

As fenomenologias da segunda geração, incluindo Heidegger, rejeitarão esta assimetria da "constituição", esta hegemonia semântica de um sujeito "transcendental" que constitui o mundo de um ponto de vista exterior ao mundo, para localizar o sentido numa "origem" não imaginável nem controlável pela subjectividade, algures na charneira da subjectividade mundana e do mundo, como é o caso do "medium do aparecer", na ontologia de Fink, ou da "carne", na ontologia do último Merleau-Ponty. Significativamente, a crítica de Luhmann ao sujeito "transcendental" de Husserl não segue esta via da interrogação de um "logos mais profundo" (que o da consciência) e "enraizado no mundo". A concepção luhmanniana do que é sentido aponta numa direç̧ão oposta ao desta metáfora das "raízes" profundamente enterradas no "solo" do mundo. Como é possível falar de "raízes" se, como escreve Fink, nos encontramos no elemento dos "Argonautas"? Para Luhmann o sentido reside nas "operações" de "sistemas" cujo paradigma são os "actos" da consciência

14 Luhmann, Die neuzeitlichen Wissenschaften und die Phänomenologie, op. cit., p. 49.

15 Husserl, Cartesianische Meditationen, Husserliana, Vol. I, p. 86. "Transzendenz in jeder Form ist ein innerhalb des Ego sich konstituierende Seinssinn". "Toda e qualquer forma de transcendência é um sentido de ser que se constitui no interior do ego".

16 Husserl, ibid., p. 88. 
intencional temporalizada, tal como foi tematizada por Husserl. Esta proximidade em relação à fenomenologia husserliana dos actos de consciência, porém, não impede Luhmann de rejeitar toda uma série de teorias do mestre de Freiburg destinadas a assegurar a omnipotência semântica e a omnisciência ontológica do sujeito "transcendental", bem como a sua "função unificadora" (Einheitsleistung) do mundo. A "eidética", o sistema de "ontologias formais" e "materiais", a teoria dos "tipos", sem esquecer, obviamente, a sempre inacabada teoria da "redução", a série das "reduções transcendentais", fazem parte dos instrumentos teóricos a que Husserl recorreu para assegurar essa unidade.

Para Luhmann, um sistema como a consciência limita-se a efectuar uma "autodescrição do mundo no mundo", ${ }^{17}$ ou seja não tem capacidade para "imaginar"18 todos os sentidos, não pode abraçar toda a "complexidade" do mundo de um ponto de vista exterior ao mundo. É isto que significa a correlação System/Umwelt e a distinção estrita que Luhmann traça entre Umwelt, mundo englobante, o correlato do "sistema", e Welt, o "mundo" que encerra a "complexidade extrema", a totalidade das possibilidades e das selecções. ${ }^{19} \mathrm{O}$ que Husserl diz do "mundo", visto na perspectiva da constituição, é até certo ponto válido para aquilo a que Luhmann chama Umwelt, correlato hetero-referencial do sistema; no entanto, é insuficiente para pensar o "mundo" no sentido de Luhmann, como "conceito sem diferença", ${ }^{20}$ ou seja sem correlato.

A motivação da crítica luhmanniana de Husserl é, portanto, muito diferente da dos fenomenólogo da segunda geração. No limite é, de certo modo, oposta. Na sua perspectiva, a subjectividade transcendental não é criticada, como na fenomenologia pós-husserliana, com o intuito de fazer valer um sentido "mais profundo", imanente à "existência", ao "ser" ou ao "mundo", inerente ao "medium" ou à "carne". Longe de pôr em causa a assimetria husserliana da subjectividade constituinte em relação ao mundo, Luhmann começa por confirmá-la com a sua diferença sistema/Umwelt, e, em seguida, amplifica-a, na medida em que os sistemas não se limitam a "constituir" o sentido de um mundo dado mas participam na "construção de complexidade", ${ }^{21}$ ou seja na construção de mundos ambientes. Se é verdade, como afirma Luhmann, que a teoria dos sistemas pode ser vista como uma "reformulação fortemente abstracta do projecto de Husserl", ${ }^{22}$ isso não impede que, no projecto do sociólogo de Bielefeld, se esteja perante uma mudança radical das questões motivadoras. O mundo husserliano dos objectos e das experiências "tipifica-

17 Luhmann, Soziale Systeme, op. cit., p. 105.

18 "Erdenken", Husserl, ibid., p. 88.

19 Luhmann, Soziologische Aufklärung 1, Opladen, Westdeutsche Verlag, 1970, p. 116.

20 A Umwelt, mundo englobante, define-se pela diferença inaugural em relação ao sistema. $\mathrm{O}$ "mundo", Welt, ao contrário, é um "conceito sem diferença", diferenzloser Begriff. Ver Soziale Systeme, op. cit., p. 283.

21 "Aufbau von Komplexität". Luhmann, Die neuzeitliche Wissenschaften und die Phänomenologie, op. cit., p. 49. 
dos" deixa de ser um grande socorro para fazer face ao problema que põe um sistema radicalmente temporal, cujos elementos são acontecimentos contingentes, "selecções" que podiam sempre ter sido outras, e que gera a sua própria "complexidade interna", o seu próprio "infinito interior". O problema que a teoria de Luhmann tenta formular não decorre do esquecimento de uma "origem", de uma experiência original cujo sentido a fenomenologia poderia recuperar por meios genéticos, arqueológicos ou hermenêuticos. Antes se trata de um problema que vem, por assim dizer, do lado oposto, de um futuro contingente a que fazem face todos os sistemas, não susceptível de ser dominado através de necessidades e a prioris.

O problema do mundo, enquanto problema da unidade do mundo, continua a ser um problema da teoria luhmanniana dos sistemas - problema herdado da abordagem husserliana da questão do mundo por meio da famosa teoria do "horizonte". A descrição do mundo em termos de "complexo de remissões" (Verweisungszusammenhang, Husserl) e de série aberta e arborescente de acontecimentos, de possibilidades ou de "selecções", faz aparecer o fenómeno mundo, como já dizia Max Scheler, como "abertura". Scheler mostrou bem o aspecto antropológico do problema. O homem é o único animal que faz por assim dizer explodir a sua Umwelt, o mundo ambiente em cuja actualidade e imediatidade o animal não humano está encerrado. Ele é o único animal capaz de se distanciar da Umwelt para aceder a um mundo propriamente dito - uma Welt caracterizada pela "abertura do mundo" (Weltoffenheit). ${ }^{23}$

A análise fenomenológica de Husserl, nas Ideias $I$, já mostrava que a "abertura" do mundo significa o acesso a uma série aberta de experiências possíveis, a um infinito de possibilidades: "Toda e qualquer experiência actual remete (verweist) para além dela para experiências possíveis, as quais, por seu turno, remetem para novas experiências possíveis, e, assim, ad infinitum" ${ }^{24}$ Mas a Weltoffenheit é um presente envenenado: Como é que um ser finito pode gerir a multiplicidade temporal dos possíveis, esse "infinito" de que fala Husserl, que se anuncia constantemente como "horizonte" do mundo?

Um princípio de solução do problema, já vista por Husserl, consiste em opor à "abertura do mundo" um "fechamento" semântico - que acresce ao próprio fechamento estrutural do sistema ou da consciência. ${ }^{25}$ É o que nota Luhmann ao escrever, em absoluta consonância com Husserl, que "todo o sentido remete (verweist) para mais sentido". "O fechamento circular destas remissões aparece (erscheint) na sua unidade como último horizonte de todo o

${ }^{23}$ Scheler, Die Stellung des Menschen im Kosmos (1927), Berna, A. Francke, 1983, pp. 38, 40.

${ }^{24}$ Husserl, Ideen zu einer Phänomenologie und phänomenologischen Philosophie I, Husserliana, Vol. III, p. 90.

25 Para Luhmann a consciência é um "sistema fechado", na sequência de Husserl, que caracteriza a consciência como um "geschlossener Seinszusammenhang", no qual "nichts hineindrigen und nichts entschlüpfen [kann]". Husserl, ibid., p. 93. 
sentido: ou seja, como mundo." ${ }^{26}$ Mas o "último horizonte" é uma simples metáfora, ou mesmo, melhor dizendo, um oximoro.

Sem dúvida que, parafraseando o que disse Wittgenstein da linguagem, se pode dizer do sentido que, apesar da luxuriante e prolífica dinâmica das remissões, ele constitui o "limite do meu mundo". De facto, tanto para Husserl como para Luhmann, no mundo, não há nada sem sentido. ${ }^{27}$ Mas a unidade que daí resulta é abstracta; não dá acesso a uma unidade do mundo, dada na experiência ou simplesmente concebível. A metáfora husserliana do "horizonte" exprime um problema, não uma solução. O conceito de horizonte promete uma "unidade" das remissões; todavia, todo e qualquer "horizonte" remete para um plus ultra, para um além desse horizonte. Tomada à letra, a metáfora do "último horizonte" encerra uma contradictio in adjecto. Daí que Luhmann acabe por constatar que, "fenomenologicamente apreendido, o mundo é uma unidade inconcebível (unfaßbare Einheit)" ${ }^{28}$ Isto significa que a teoria dos sistemas vai ter de ir além da fenomenologia no tratamento do problema da unidade do mundo, o que quer dizer abandonar a perspectiva da fenomenologia, e desdramatizar uma provável ausência de unidade.

Além de expor sucintamente a resposta luhmanniana a este problema, podemos utilizá-lo para mostrar a divisão das águas que o seu tratamento vai trazer entre fenomenologia e teoria dos sistemas, e, dentro da fenomenologia, entre diferentes propostas fenomenológicas de solução.

Uma primeira solução do problema do mundo e da sua unidade é fornecida pela fenomenologia de Husserl, por recurso a uma série de instrumentos teóricos, à frente dos quais o sistema dos a prioris e das "ontologias", formais e materiais, as "essências" e as "necessidades de essência", e, sobretudo, o "sujeito transcendental" e as múltiplas "reduções" (cartesiana, egológica, psicológica, lebensweltliche, etc.) tentadas para captar e fixar fenomenologicamente o transcendental. O grande inconveniente desta solução é sinteticamente apontado por Merleau-Ponty, numa passagem já acima citada, com a evocação de toda uma série de fenómenos que remetem para transcendências "que nos ultrapassam", o que significa que "ultrapassam" todo e qualquer "sujeito transcendental".

Um outro modo de abordar o problema consistiria em seguir as sugestões centrais do último Husserl, contidas no conceito de Lebenswelt. A Lebenswelt é por assim dizer um mundo constituído, ou "criado" (Merleau-Ponty), à medida da finitude, um mundo no qual a própria finitude seria constitutiva, e a infinitude uma ilusão "idealista". A unidade de um tal mundo, apesar de haver

26 Luhmann, Soziale Systeme, op. cit., p. 105.

27 As queixas relativas ao pretendido "absurdo" da existência ou à "falta de sentido da vida" mais não são do que expressões metafóricas, literárias, se quisermos, de paradoxos do sujeito moderno, ou seja de uma realidade que, como tal, se for observada, descrita e analisada tem, obviamente, sentido. 
nele focos de estranheza, coisas que nos ultrapassam, já não seria necessariamente "inconcebível". O problema da unidade desloca-se do "horizonte" (ou seja do "ad infinitum" das remissões) para passar a residir no "solo" do mundo. A tarefa da fenomenologia seria, literalmente, de aprofundamento. Ela pode ser concebida, como propõe Fink, como revelação do sentido do "movimento do aparecer", considerado "medium absoluto" do "reinar do mundo" (Walten der Welt), ${ }^{29}$ ou, como propõe Merleau-Ponty, como "fenomenologia da fenomenologia", ou seja como "descrição indirecta" reveladora das intenções da intencionalidade enquanto enraizada no mundo, e, assim, de um "logos mais profundo" do próprio mundo. A unidade do mundo estaria garantida, na perspectiva da finitude constitutiva, através de uma lógica espacial, de uma topo-lógica, da "criação" de mundo. As ontologias da "carne" (Merleau-Ponty) e do "medium absoluto" (Fink) obtêm unidade pela referência ontológica a um "mesmo e único" mundo. A sua vantagem - que também é um inconveniente - está na desdramatização que operam do factor temporal e modal da "abertura" do mundo. ${ }^{30}$ É difícil, nesta perspectiva, ver o lado negativo da multiplicação incontrolada de possibilidades contingentes, ou seja, o problema que coloca aquilo a que Luhmann chama "complexidade".

Finalmente, na teoria dos sistemas de Niklas Luhmann, assistimos a um indubitável retorno a Husserl numa formulação do problema do mundo, embora não na sua solução, marcada pela problemática do "horizonte" (ou seja do infinito). Isto é uma via que, manifestamente, contorna as "ontologias" da finitude que caracterizam as fenomenologias da segunda geração.

No primeiro período da sua obra teórica, marcado pela controvérsia com Jürgen Habermas em torno do que deveria ser o "conceito fundamental (Grundbegriff) da sociologia", Luhmann encontrou na fenomenologia de Husserl, em particular no seu conceito de "sentido", os instrumentos que lhe permitiam escapar à abordagem dos fenómenos sociais através das teorias clássicas da "acção" e da "praxis" (Aristóteles, Weber), de modo a dar conta do seu carácter modal e contingente, e a interpretá-los como uma "ordem emergente" (conceito proveniente das teorias dos sistemas e da evolução) que toma forma no seio da complexidade do mundo. Ao optar pelo sentido como "conceito fundamental da sociologia", ${ }^{31}$ o sociólogo de Bielefeld opõe-se frontalmente à opção de Habermas pela linguagem, e pelo linguistic turn no plano metodológico, que vê nos speach acts uma "acção comunicacional", e, a partir daí, a

29 Fink, Sein, Wahrheit, Welt, op. cit., p. 130.

30 Daí que Merleau-Ponty, por exemplo, a partir da ontologia do "être sauvage", que constitui o "único e mesmo" mundo, postule que "o tempo serial, dos 'actos' e das decisões seja ultrapassado" e "o tempo mítico reintroduzido". Le visible et l'invisible, p. 222. Cf. igualmente ibid., p. 238.

31 "Sinn als Grundbegriff der Soziologie", tal é o título do primeiro ensaio de Luhmann no livro-debate Theorie der Gesellschaft oder Sozialteleologie escrito, em 1970, em conjunto com Habermas. 
possibilidade de integrar a teoria da sociedade na tradição ocidental da "filosofia prática", no sentido não só aristotélico mas igualmente, e sobretudo, kantiano, ou seja moral, deste conceito.

Para Luhmann, a fenomenologia de Husserl permite "um acesso directo e sem pressupostos ao problema do sentido", ou seja sem os pressupostos teleológicos, éticos ou metafísicos das teorias tradicionais da acção. $\mathrm{O}$ acesso ao problema do sentido "é aberto por uma descrição fenomenológica do que é verdadeiramente dado num viver provido de sentido (sinnhaftes Erleben)". ${ }^{32}$ Isto vai permitir uma semantização do mundo que faz com que este deixe de ser visto como uma "totalidade de coisas" para passar a ser encarado como um "sistema de remissões" (Verweisungszusammenhang), as quais remetem não só para objectos ou estados de coisas do mundo "exterior", mas para os próprios actos da consciência, que são acontecimentos no tempo, e não só para realidades mas para possibilidades. Como já se disse, Luhman rejeita os instrumentos do idealismo husserliano destinados a conferir ordem e unidade a este mundo semantizado e modalizado que deixou de ser uma simples universitas rerum. Mas rejeita igualmente as soluções "ontológicas", anti-idealistas das fenomenologias da segunda geração. Entre a subjectividade e o mundo não há nenhuma "medium", nenhuma "comunicação", nenhum quiasma do sensível, nenhum "logos mais profundo" que possa ser interpretado por uma hermenêutica do mundo da vida. O conceito husserliano de sentido, entendido por Luhmann na sua forma modal mais formal como actualização da intencionalidade enquanto possibilidade, como "selecção", permite-lhe escapar à ontologia fenomenológica e à lógica do "aparecer". A teoria dos sistemas concentra-se, assim, no problema do "excesso do possível" (Überfülle des Möglichen) ou das "remissões" com que o viver consciente é confrontado a cada instante. O problema deste "excesso" modal é tanto mais agudo quanto a consciência, enquanto sistema temporal, e constituinte do seu tempo, está submetida a uma “obrigação de selecção" (Selektionszwang). ${ }^{33}$

Deste ponto de vista, o mundo começa por ser apreendido negativamente, enquanto "problema dos sistemas" ou "complexidade extrema", e o sistema, por oposição, como uma "ilha de menor complexidade". Para Luhmann, o mundo não é um sistema, nem deve ser pensado como sistema. Tal seria, justamente, a perspectiva da "metafísica" que a teoria dos sistemas afirma rejeitar.

Neste ponto convém sublinhar um traço essencial do "sistema" luhmanniano, que o opõe em absoluto ao conceito homónimo que encontramos no idealismo alemão, em particular na sua versão hegeliana. No sentido de Luhmann, o "sistema" não tem como ponto de partida (e de chegada) o "universal", não é um des-envolvimento (no sentido original, literal e concreto, deste

32 Luhmann, in Habermas; Luhmann, Theorie der Gesellschaft oder Sozialtechnologie, op. cit., p. 31 . 
termo, similar ao do alemão Ent-wicklung) orgânico da "totalidade", mas, ao contrário, do ponto de vista da consciência individual, um conjunto de relações destinadas a ordenar uma vida, a estabelecer uma ordem no tempo, sem perder a referência ao mundo ambiente. ${ }^{34}$ Quando dizemos que alguém "montou um sistema", sabemos que o fez para se defender da contingência e do tempo. Nesta perspectiva é o "sistema" que confere unidade ao mundo, o qual deixa de ser "complexidade extrema" para passar a ser Umwelt, "ambiente" do sistema, complexidade até certo ponto dominada. A Umwelt é o mundo visto e organizado na perspectiva de um sistema, o qual só apreende, obviamente, o que lhe interessa. Isto é válido, tanto para os sistemas de tipo consciência, como para os sistemas a que Luhmann chama "sociais". Estes últimos não existiriam sem os "psíquicos", sem as consciências, os quais, por seu turno, estão dependentes dos sociais, muito mais potentes que as fracas consciências para tratar a complexidade do mundo e o seu excesso de possíveis.

Do ponto de vista de cada sistema, que responde à "abertura do mundo" por um "fechamento operativo", o mundo, enquanto ambiente de um sistema, tem uma unidade, está centrado na diferença específica desse sistema relativamente à Umwelt. Isto significa que o mundo, enquanto totalidade virtual dos sistemas é, como escreve Luhmann, "multi-cêntrico"35 ou "acêntrico", ${ }^{36}$ o mesmo é dizer sem unidade. A teoria de Luhmann não aceita algo como um sistema dos sistemas ou um sistema dominante susceptível de unificar o mundo ou, no caso dos sistemas sociais, a sociedade. ${ }^{37}$ Apesar disso, o sociólogo de Bielefeld não desiste de conferir ao mundo no sentido lato, para lá dos mundos ambientes, uma "unidade" que ocupa o lugar do "centramento tradicional do conceito de mundo por referência a um 'centro' ou a um 'sujeito', o qual é abandonado mas não é pura e simplesmente suprimido sem contrapartida". ${ }^{38} \mathrm{O}$ que poderá significar esta "unidade"?

É significativo que, para a explicar, Luhmann invoque o conceito husserliano de "horizonte do mundo". Para ele, trata-se de preencher com uma teoria aquilo que em Husserl não vai além de uma metáfora espacial e geográfica, a qual, apesar de não ser mais que isso, fornece uma preciosa indicação. O teórico dos sistemas nunca poupou elogios e homenagens ao fundador da feno-

34 Esta inversão do conceito hegeliano de "sistema" não é nova. Uma inversão semelhante do conceito dialéctico de sistema já se encontra na obra de Franz Rosenzweig Der Stern der Erlösung (1921).

35 Luhmann, Soziale Systeme, op. cit., p. 284.

36 Idem, ibid., p. 106.

37 Na filosofia prática de Aristóteles, a política, enquanto technê e epistêmê "arquitectónica", ou seja ordenadora (Eth. Nic., 1094a 6 ss.), é o "sistema social" que desempenha um tal papel unificador. A teoria luhmanniana dos sistemas tem a pretensão explícita de rebater este modelo hierárquico e unificador que domina toda a tradição da "filosofia prática" ocidental. Ver, por exemplo, N. Luhmann, "Gesellschaft", in Soziologische Aufklärung 1, op. cit., pp. 137 sq.

38 Luhmann, ibid., p. 284. 
menologia. Podemos dizer que, do ponto de vista de Luhmann, a "unidade do mundo" se poderá compreender como uma semantização e uma temporalização do "horizonte".

Semanticamente, a unidade do mundo reside no facto de todos os sistemas operarem com sentido. Em termos de sentido, "partindo de qualquer ponto, pode-se chegar a todas as outras possibilidades do mundo". Mesmo se o efeito das remissões semânticas tem por contrapartida um "mundo acêntrico", o "horizonte do mundo", enquanto "último horizonte", permite ir além de qualquer limite semântico, ou seja do horizonte local de qualquer sistema determinado. Isto torna possível "suprimir as diferenças de perspectiva entre os sistemas particulares" 39 e, portanto, obter uma unidade. Tal significa que o sujeito "transcendental" unificador do mundo é substituído pelo fenómeno anónimo da "diferenciação do indiferenciado", ou seja da "formação espontânea de sistemas" (Systembildung) que "operam com sentido". ${ }^{40}$ A "reformulação da fenomenologia" em termos de teoria dos sistemas, de que fala Luhmann, é uma naturalização sui generis da fenomenologia transcendental, centrada numa "vida" que gera sistemas semânticos.

Por outro lado, a teoria dos sistemas tenta pensar a unidade do mundo em termos temporais. A estrutura husserliana do infinito do "horizonte" é deslocada para o tempo, é temporalizada. O sistema luhmanniano é uma forma eminentemente temporal, ${ }^{41}$ coisa que, aliás, também não é avessa à concepção husserliana da vida da consciência. A consequência da temporalização do "horizonte" produz uma verdadeira inversão, relativamente à fenomenologia, do lugar temporal que constitui o ponto de fuga para que remetem, em última instância, as remissões (Verweisungen); ou seja, em termos simples, a unidade

39 Luhmann, Soziale Systeme, op. cit., p. 106.

${ }^{40}$ Luhmann, ibid., p. 284.

${ }^{41}$ Ao contrário, nomeadamente, das "estruturas" de ordem supra-temporal ou transcendental, razão pela qual Luhmann considera a sua teoria dos sistemas uma "teoria pós-estruturalista". N. Luhmann, "Die Autopioesis des Bewußtseins", in Soziale Welt, 36, 1985, p. 407; este texto foi reproduzido em Luhmann, Soziologische Aufklärung 6, VS Verlag, Wiesbaden, 2005. Tomando a "consciência" como modelo, Luhmann expõe a essência temporal dos sistemas nos termos seguintes: "Há sistemas autopoiéticos que são compostos exclusivamente por acontecimentos, ou seja por elementos que com o seu aparecimento desaparecem logo a seguir. Isto acontece sobretudo no caso da consciência. Os elementos da consciência são adquiridos por modificação de elementos da consciência. A consciência existe como auto-transformação. O tempo tem sobre tais sistemas um efeito que não se restringe apenas ao plano das estruturas, no sentido em que as estruturas devem ser mantidas flexíveis e mutáveis, a fim que o sistema, em caso de necessidade, se possa adaptar a novas condições do meio ambiente. Deve-se antes pensar que o tempo já está instalado no sistema em funcionamento, antes de toda e qualquer adaptação, na forma da dissolução permanente dos seus elementos. O sistema é, por isso, obrigado a tornar-se a si próprio irreversível através da constante formação de novos elementos, ou seja a acumular uma história e, desta forma, a submeter-se, por assim dizer por necessidade própria, à irreversibilidade do tempo do mundo (Weltzeit)". N. Luhmann, ibid., p. 403. 
semântica do mundo não reside numa experiência "originária" cujo sentido teria de ser recuperado por meios genéticos, arqueológicos ou hermenêuticos; é, antes de mais, uma unidade constantemente e recorrentemente projectada no futuro. Por esse motivo ela é caracterizada por Luhmann como "unidade terminal" ou de "fecho" (Abschlußeinheit). ${ }^{42} \mathrm{O}$ "último horizonte", ou a unidade do mundo, é, pois, puramente temporal, projectado num futuro inatingível, insusceptível de ser vivido, inimaginável.

Os problemas que restam são questões, por assim dizer, de filosofia prática, que têm sempre de ser colocadas, como na fenomenologia, na perspectiva da primeira pessoa. Como orientar as nossas vidas finitas num mundo de sistemas funcionais cuja "unidade" remete para um futuro propriamente impensável? Mesmo se o teórico dos sistemas considerava que questões deste tipo não podem nem devem ser colocadas no âmbito da sua teoria, para o "sistema consciência" elas não podem ser iludidas. A teoria dos sistemas fornece, apesar dos limites que se impõe, informações sobre a natureza do "social" que poderão ser úteis para formular com alguma pertinência, no mundo da vida que é o nosso, inadiáveis questões filosóficas.

${ }^{42}$ Luhmann, Soziale Systeme, op. cit., p. 284. 